\title{
THE CORRELATION OF HIGH SCHOOL CHEMISTRY AND DAILY LIFE.1
}

\author{
By John C. Hessler, \\ James Millikin University, Decatur, Ill.
}

The topic of the symposium relates itself immediately, as I see it, with the important movement gathering head throughout our country to conserve, in ways and to an extent undreamed of by the fathers, the life, the effort, and the resources of our people. No phase of the conservation movement is more promising than the attacks being made upon the strongholds of drudgery. If man's activities be classified into play and work, then drudgery is zeork gone to seed. Its characteristic is performance without motive; hence it is monotonous, unrelated to creative work, and incapable of being performed with enthusiasm. We have yet to learn, as a people, that no one does us a greater service than he who finds a way of injecting into the thousand monotonous tasks that must be performed in the kitchen and the factory, and on the farm, the purpose and satisfaction of real work, coupled with some of the exhilaration of play.

Now, the modern educator, in studying the activities of the child, finds that drudgery is not confined to kitchen, farm, and factory. With an industrial system entailing so much monotonous labor for the adult, it is not surprising that the work of the school is found to be full of drudgery for the child. Here, again, we have a multitude of tasks performed, not with the interest inherent in play, nor with the purpose of significant labor, but rather with only one object; to meet the demand of the masterthe teacher. No teacher can have failed to see, and to deplore, the character of work done on so low a plane, and with so arbitrary a standard. The teacher may not lightly recommend that the pupil drop a course in which he is not interested. The point to be noted is that the nature of the pupil requiring teaching, the equipment of the school for teaching, and the experience and training of the teacher constitute resources of our civilization, and they must be conserved if that civilization is to accomplish its purpose. Teacher, pupil, and school must remain together long enough to permit the transformation of the untrained child into the useful, thinking, self-governing citizen. To this end the teacher MUST find motives which will infuse into school work the

\footnotetext{
${ }^{1}$ Read before the chemistry section of the Central Association, I,ewis Institute, Chicago, Dec. 1, 1911.
} 
interest, the purpose, and the methods that obtain in work which the child considers worth the doing.

The need of motivation is not confined to the grade schools, nor to nonscientific subjects. Nowhere are motives more needed to give enthusiasm and purpose than in the laboratory sciences. When laboratory work was introduced into the high schools, the argument for its adoption was that it would stimulate the interest of the pupil, for the reason that he would be able to repeat the experiments of the great masters of science, and so have a practical basis for applying to daily life what must otherwise remain, for him, merely wonderful, unrelated facts. But an experience of some years in teaching chemical science convinces me that the attitude of the average pupil to science is in no way different from his attitude toward other studies. As with mathematics, language, and history, so with chemistry; the average pupil does not work with enthusiasm, as though compelled by self-interest, but mechanically, and in the least finished way which the teacher will accept. This, be it understood, applies to all schools, even to the universities. The task is done essentially to pass the criticism of the teacher, not to attain to a standard of excellence set up by the student himself. Because the stimulus is all from the teacher, the student does not think of articulating either text-book lesson or laboratory exercise with other knowledge. Least of all does he think of the school task as he would of similar work in the world outside. For him each lesson is an isolated exercise to be learned, each course a nightmare to be successfully "passed" and never heard of more. No wonder that we cannot get our pupil to remember his exercises from day to day, and that we find him entering each new course with a minimum of knowledge and experience from the one that preceded it.

What are the causes of the pupil's attitude toward the science studies, and particularly toward chemistry? At the risk of duplication and of omission I give the causes as four in number:

I. The idea that there is no vital connection between chemistry as taught and as applied in the activities of the home, the farm, the factory, and the community is borne in upon the pupil, not only by his own observation, but by the attitude of the school, the home, and the people at large.

2. The character of the topics studied, or not studied, in the high school course of chemistry. The most interesting things, from the point of view of curiosity, are left out.

3. The logical arrangement of the chemistry course makes it 
a mechanism that is "good" for the pupil, but for which the pupil, as he is not in the secret, cannot see the reason.

4. The strict differentiation of chemical science from physical and biological science and the natural inference, on the part of the pupil, that it is also differentiated strictly from the science of common life.

The operation of the first cause-remoteness of the work done in the laboratory from that done in real living-may be looked at from several angles. One observation is that the laboratory ap-paratus is totally different in form from the apparatus with which the child is familiar. Again and again have I noted that girls specializing in domestic science, who were using the gas stove daily, failed to recognize it as a Bunsen burner. This is probably an extreme case, but it illustrates well the lack of correlation in the mind of the student while he is performing his laboratory work. The remedy here, it seems to me, is to call attention, by actual demonstration of the commercial and household forms of our laboratory equivalents, to the relation between the two. The teacher makes a mistake if he sends the pupil to the business men dealing in the commercial forms of apparatus. Even if these merchants understand fundamental principles, and they rarely do, they either cover their knowledge with technical jargon, or refuse to take the questions of the pupil seriously.

To take another illustration: Our chemistry courses give the properties and reactions of water, but they do not go into sufficient details regarding water in the house. We cannot assume that the pupil knows the details of a water or plumbing system, neither can we tell him to go to his home to find out. Most pupils, especially girls, to say nothing of the parents of pupils, are afraiơ to dissect apparatus in actual use because they are not certain they can replace the parts correctly. Will it detract seriously from the value of the study of water if the teacher shows, by actual dissection, the construction and use of meter, filter, faucet, trap, heater and tank, and the methods used to secure watertightness in the system? We hurry over such topics too rapidly, taking things for granted, forgetting that some, at least, of our pupils do not have access to all these modern improvements, or, if they do, they see only the exterior, and have no conception of the way in which the mechanism works.

As the second cause of "severed relations" between chemistry and common life I have placed the character of the subjects studied, or NOT, studied, in our modern chemical courses. The earlier 
lecture course method of chemical teaching was full of showy experiments, in which changes of color, sudden explosions, and noxious odors played leading roles. The student who was permitted to work in the laboratory repeated these experiments, or devised new ones of the same pyrotechnic sort. The result was no end of interest, but little real insight into the methods of the science. What impresses one who knew the earlier method is the list of substances not prepared in the modern course. Exigencies of large classes, and, more important, danger to life, limb, and eye, have driven out of the course practically all experiments with, and preparation of unstable compounds. A science that was once all life and energy has become respectable, safe, and prosaic. I am not contending that our selection of topics is not better than the old one, but I do assert that it has not equally strong motives of interest for the pupil. Can we find motives that will furnish as real a stimulus for the determination of the equivalent weights of magnesium and hydrogen, for the weight of a liter of oxygen, and for the study of solutions, as for the preparation of nitrogen iodide, chlorine dioxide, and nitroglycerine? I believe we can, but it goes without saying that we must appeal to a deeper interest. For one thing, we need to restore some of the rejected topics of the earlier science. To illustrate: The average pupil in chemistry knows nothing about an electric battery, even if he has studied physics. His supply of current came out of wall, floor, or ceiling. He knows nothing of electric charges, because the study of frictional electricity has been cast aside. Even the most fundamental physical phenomena are nothing to him. A recent text-book uses the abnormal osmotic pressures of aqueous salt solutions as evidence of dissociation in solution, but nowhere defines or describes osmotic pressure.

It is vain for the chemistry teacher to say that problems of sanitation belong to household science and those of osmotic pressure to physics. Pupils studying chemistry may not have taken domestic science and physics, or if they have studied these subjects, may not have understood them owing to lack of knowledge of the chemical principles involved. We must remember that the average pupil, in spite of the advanced mechanical and commercial age into which he is born, takes about as long for his development as his grandfather before him, and he cannot overleap all the intermediate stages of scientific thought without being hopelessly stranded.

My third cause was the logical system according to which 
chemistry is presented. No one would insist more than I upon a rationally consecutive order of topics for the formal course in chemistry. But it does not follow, after a general plan has been adopted by the teacher, that all the pupils need exactly the same chemical pabulum from day to day. Most have preferences, and we do our work with best results when these preferences receive some consideration. The logical order is not the order in which we become acquainted with common substances. Milk, butter, flour, meat, wood, stone, porcelain, cloth, these are much more natural to us than hydrogen and chlorine. Even natural water and air are very complex. We begin chemistry, and I believe correctly, with the study of gases, but the gaseous condition is not readily comprehended. Hence, when we present to the pupil hydrogen and oxygen, while we are really choosing the simplest forms of matter, we appear to be taking those farthest removed from common experience. The remedy is to prepare not two, but many gases, and to show their resemblances and their easily demonstrated differences, so that the pupil can get a more definite conception of what we mean by a gaseous substance.

But I believe a more radical departure still must be made from the strictly logical order to bring chemistry "back to the people." To return again to the topic of "water," there are few regions in which there are not several sources of the supply. The tests for chlorides, nitrites, sulphates, organic matter, and hardness are easily made. By means of miniature water surveys these tests can be applied for months, instead of once or twice, and the content of the water samples correlated with weather, rain supply, etc. Milk surveys, butter surveys, studies of the salt, sugar, vinegar, coffee supplies, of patent medicines, etc., will give zest to the formal study of our science, and will relate it to our community life. Ultimately, the permanence and the value of any activity must be measured by the community standard.

Such a synthesis of knowledge would remove the cause I have placed fourth; namely, the differentiation of the sciences from one another. This differentiation, no matter how desirable it may have been in the past, nor how necessary it may still seem to the investigator, has gone too far to be of benefit to the pupil in the secondary school. This worship of differentiation was well expressed by one of its devotees when he stated, in response to the question as to whether general science was desirable for the first year of the high school, "I do not want the student taught general science because I wish him to know what science he is study- 
ing." As I see it, it is important for us to enrich any science by bringing into it the discoveries and conclusions of the others. Biology teachers are wont to deplore the inadequate conceptions which their pupils, not to speak of the general public, get of organic evolution. I commend the "Electromotive Series of the Metals" to them as an illustration of evolution based upon environment. The texts usually state that in this series the metals that precede replace those that follow, in the solutions of their salts. This is an interesting, but isolated, chemical fact. The series is a great deal more interesting to the student if it is made to reveal other chemical facts. Thus, the stability of the oxides $d e-$ creases as we proceed, so that only mercury, and those that succeed it, can be obtained by heating the oxides, hence only these metals will not rust under natural conditions. Still more illuminating is the observation that the metals group themselves on each side of hydrogen, and that the metals that were to be used in the simple voltaic cell were definitely conditioned by their positions in the series. But the greatest interest of all is aroused when we ask what metals were likely to be discovered first by man, and what the order of the discovery of the other metals would be. This picture of the evolution of industrial civilization is of sufficient interest to even average pupils to require no further motivating.

To summarize, then; to motive high school work in chemistry I would first purposely bring in commercial and domestic apparatus and show its working in detail, even if $I$ had to sacrifice a little of some of the commonly accepted topics, and, in the second place, I would, early in the course, myself contribute, and ask the students to contribute, to a list of topics of a chemical nature capable of investigation in the community served by the school. I would assign these topics, as far as possible according to preference of the student, for work during the whole year, or as much of it as seemed desirable, for work of an investigative character. Moreover, if I had to choose, I would give the most interesting and productive topics to those students for whom the subject required the most motivating. Such work would do service of another kind not contemplated at first, viz.; it would motive the work of the teacher himself and relate his own work with that of all the other significant factors that make for a more sane and fruitful community life. 